\title{
IMPLEMENTATION OF WOMEN SELF SECURITY BAND
}

\author{
Ch.Ganapathi Pullaji \\ Department of ECE \\ Assistant Professor \\ Vsm college of engineering \\ Ramachndrapuram, AP, INDIA \\ K.Devi Saroja, V.Sai Nagarjuna, M.Avinash,, G.Satya Divakar \\ Department of ECE \\ Vsm college of engineering \\ Ramachndrapuram, AP, INDIA
}

\begin{abstract}
From past few years, India has gone through many changes. Still, women are facing social challenges and are often victims of abuse and violent crimes. Hundreds and thousands of incidents of physical abuse are happening to women every day. The main aim of our project is to provide a message to predefined contacts like parents, friends, media, etc. with an instant location. The Nirbhaya case in Delhi triggered over the nation was the greatest motivation for our project. The aim of this project is to develop a self- defense system especially for women to protect themselves from present day physical harassments. This band has wide range of features and functionality like providing instant location of women who is bad situations. The basic outline of project is to secure the women from the present worse situations that are occurring in our society. It mainly work based on an Arduino and GSM module. It consists of a shock circuit and GPS system which helps the women when she stucked in bad situations. It helps eventually in present scenario.
\end{abstract}

Keywords- GSM, GPS, ELECTRICSHOCK, WOMEN SECURITY, ACCELEROMETER, ARDUINO

\section{INTRODUCTION}

Now a day, the women's safety is becoming the major issue, such apps do exist, and they are equally smart to confiscate the victim's phone. Here we introduce a band, which provides the Protection of women. This helps to identify the women and call on resources to help from bad situations. Main purpose of this device is to provide safety and security. As being an independent nation women's are not safe even today. There should be some accurate measures for the security of the women's. Nowadays there are many applications developed for the women security but main drawback of these applications is it required initial interaction of women and that situation it is not possible here we made a one smart band and android application. This project work automatically based on Accelerometer and shock circuit. This application used by giving the shock to the attacker and protect her. If she is in danger then message is send to the family member and nearby police station with the GPS location of victim. Also this emergency message is send on application so it is provide social platform in future applications.

The design is implemented using an Arduino Uno interfaced with accelerometer, GSM and GPS systems in a modular form to be adaptable to different types of location tracking. Depending on the total design of the system, the hardware and software of the system is a real-time monitoring system where the situation of women and location details in order to provide immediate help. The woman can protect herself by rotating her hand thereby it produces the electric shock and helps to deter the person harassing her. Demonstrate the system

capability in providing real-time response by software is introduced in embedded $\mathrm{C}$ language. Using the location information supplied by this system, the location is traceable using GPS through Google Maps.

\section{LITERATURE SURVEY}

The system allows for knowing the exact location of the women who have this device, when the band is tapped and accelerometer, which is at predetermined angle, and then the message is sent automatically to selected contact list. That SMS containing location information in terms of Latitude and Longitude contains a shock mechanism for defense back. It sends the location to predefined contact numbers in the form of latitude and longitude. When the victim attacks to women that time shock circuit is used to punish the attacker for self-defense. 
III

EXISTING SYSTEM

In this existing system, monitoring system is not there for girls, it may create many problems for them and also no safety mechanism to safe the girls from them misbehavior activities. In addition, there is no alert system for the girl's safety, it should be done by manually only. Now days there are plenty of bands for women safety but they are based on body temperature and blood pressure, which can't help properly. All the available bands or systems must be connected to the GPRS service to work properly, hence cannot be used during emergency if there is no internet connectivity. Mischance in arriving rate and are operated based on body temperature and blood pressures.

\section{PROPOSED SYSTEM}

The block diagram of our proposed system is as shown in Fig..1:

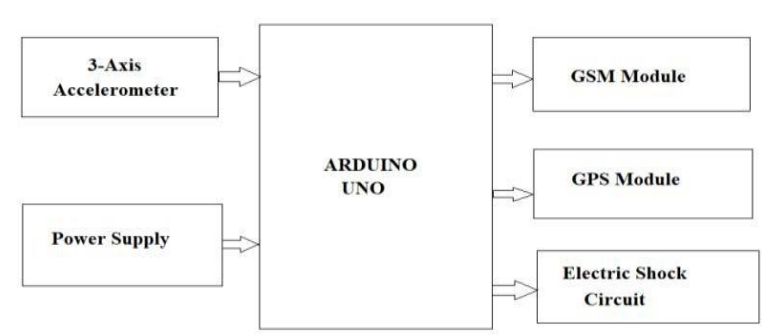

Fig.1 Block Diagram

The block diagram consists of the following hardware components.

\section{A. ARDUINO UNO}

ATmega328p is a microcontroller board. It consists 14

digital input/output pins which 6 can be used as PWM outputs, 6 analog inputs, a power socket, an ICSP header, a USB, a reset button, and a ceramic resonator of $16 \mathrm{MHz}$ 's. It should connect it to a computer with a USB cable simply or power it with an AC- to-DC adapter or battery to get started.

\section{B. GPS MODULE}

The Global Positioning System is a location tracker. It tracks the current location in the form of longitude and latitude. The GPS Coder Module used this information to search an exact address of that location as the village name, nearby street mark etc. That is connected to USART of the microcontroller provides timing services navigation, and reliable positioning to worldwide users on a continuous basis in all weather, day and night, anywhere on or near the
Earth. The system will only send the longitude and latitude through SMS when in case GPS is disabled. So, Internet is mandatory.

\section{GSM MODULE}

GSM module is used to establish communication between a computer and a GSM-GPRS system, which is developed in1990. GSM SIM card is inserted within the mobile device to send and receive the messages victimization GPRS. It operates at either the $900 \mathrm{MHz}-$ $1800 \mathrm{MHz}$ frequency band.in this system, we can use any one module from GSM SIM 800A or SIM 900A.In any GSM module SIM must be inserted to send the message from it.

\section{ACCELEROMETER}

The accelerometer MPU6050 IMU has a 3-Axis gyroscope and accelerometer integrated on a same chip. The gyroscope measures rate of change of the angular position over time, or rotational velocity along the $\mathrm{X}, \mathrm{Y}$ and $\mathrm{Z}$-axis. The output present in the units of degrees/second, so in order to get the angular position we just need to integrate the angular velocity.

\section{E. SHOCK CIRCUIT}

For implementing the shock circuit we are using the circuits involved in electric shock pen or chewing gum available in market. We are using basic transistor circuit to activate the shock circuit in band.

\section{F. POWER SUPPLY}

12 volts $(12 \mathrm{~V})$ rechargeable battery is used to power the circuit.

\section{METHODOLOGY}

The woman needs to wear this device to protect herself from unpleasant situation. This device starts working when the hand of women rotates in particular angle then it the activates the electric shock circuit and produces shock to the attacker and with help of GSM and GPS the instant location of women can be shared to selected contact list. so, that the women can save herself.

The angle of the hand to be rotate is be done with accelerometer module where both accelerometer and gyroscope integrated on single chip. The gyroscope gets the angular position and accelerometer gets gravitational acceleration. This entire process works based on a battery in the band.

\section{RESULT AND DICUSSION}

The women who's in bad situations needs to wear this device and by rotating her women in particular angle 
produce an electric shock to attacker and also produce location to selected contact list.

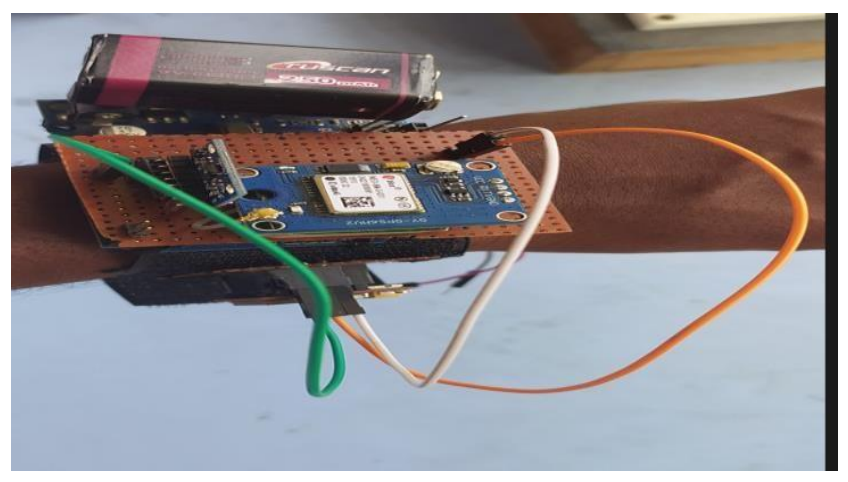

Fig.2 Result of Women Self Security Band

When the women in bad situations this band plays vital role. The women wearing this band needs to rotate her hand in particular angle where the angle is predefined in source code. After rotating her hand the band, turn ON to work. It simply provides a message to particular group of people with the location of the women stucked and mainly, the special of this band is to provide shock to the attacker. So, that the women can escape easily from bad situations.

\section{CONCLUSION}

This nature of an awareness plays a crucial role towards providing Women Safety in the fastest way possible in a self- defense manner. The proposed design will deal with critical issues faced by women in the recent past and will help solve them through technological. With further innovation and research towards this project can be implemented in different areas of security and surveillance. For desired area, this system can perform the real time monitoring.

Finally, the conclusion is that there are many selfsecurity bands are available in the present-day market. Nevertheless, they are based on body temperatures and blood pressures. So there is a chance of misalignments. However, by using this self-security band, there is no chance of misalignments and errors.

\section{ACKNOWLEDGMENT}

The researchers of this paper are highly grateful to independent reviewers for their strict condemnation of this work, which helps the writers to reorganize the work in excellence.

\section{REFERENCES}

1. M. Pramod, Ch V. Uday Bhaskar and K. Shikha.Iot wearable device for the safety and security of women and girl child. Volume 9, Issue 1,January 2018, pp. 8388, Article ID:IJMET_09_01_010

2. Bhilare P, Mohite A, Kamble D, Makode S, Kahane R (2015) Women Employee Security System using GPS And GSM Based Vehicle Tracking. International Journal for Research in Emerging Science and Technology 2: 65- 71 .

Premkumar P, CibiChakkaravarthi R, Keerthana M, Ravivarma R, Sharmila T(2015) One Touch Alarm System For Women's Safety Using GSM. International Journal of Science, Technology \& Management 4: 1536-1539.

4. Bharadwaj N, Aggarwal N (2014) Design and Development of Suraksha-A

5. women Safety Device. International Journal of Information \& Computation Technology 4: 787792.

6. Baishya BK (2014) Mobile Phone Embedded With Medical and Security Applications. IOSR Journal of Computer Engineering 6: 30-33.

7. Mand apati S, Pamidi S, Ambati S (2015) A Mobile Based Women Safety Application (I Safe Apps). IOSR Journal of Computer Engineering 17: 29-34.

8. Chougula B, Naik A, Monu M, Patil P, Das P (2014) Smart Girls Security System. International Journal of Application or Innovation in Engineering and Management 3: 281-284.

9. Miriyala GP, Sunil PVVNDP, Yadlapalli RS, Pasam VRL, Kondapalli T, et al.(2016) Smart Intelligent Security System for Women. International Journal of Electronics and Communication Engineering and Technology (IJECET) 7: 41- 4 